\title{
Plasma surface chromizing of P110 oil casing tube steel for improving corrosion and wear resistance purposes
}

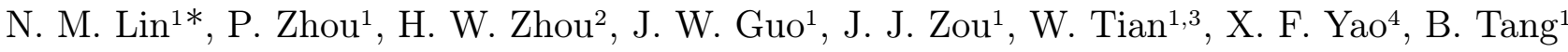 \\ ${ }^{1}$ Research Institute of Surface Engineering, Taiyuan University of Technology, Taiyuan 030024, P. R. China \\ ${ }^{2}$ No. 52 Institute of China Ordance Industries Group, Baotou 014034, P. R. China \\ ${ }^{3}$ China United Northwest Institute for Engineering \& Research, Xi'an, 710082, P. R. China \\ ${ }^{4}$ School of Materials and Chemical Engineering, Xi'an Technological University, Xi'an, 710032, P. R. China
}

Received 5 August 2014, received in revised form 2 December 2014, accepted 2 December 2014

\begin{abstract}
In this work, chromizing coating was prepared on P110 oil casing tube steel by means of plasma surface chromizing to improve its surface performance and prolong its service life-time. Electrochemical experiments, including open circuit potential (OCP) and potentiodynamic polarization were conducted in $\mathrm{CO}_{2}$-saturated simulated oilfield brine to exam the corrosion resistance of the chromizing coating. Wear resistance of the chromizing coating was investigated using reciprocating type tribometer under dry sliding against GCr15 steel counterpart. The experimental results obtained herein revealed that chromizing coating was uniform and compact; the obtained coating exhibited higher open circuit potential and lower corrosion current density in comparison to P110 steel. Chromizing coating with higher surface hardness showed better wear resistance than that of P110 steel. Subsequently, plasma surface chromizing could be considered as a potentially effective method for improving the surface performance of P110 steel.
\end{abstract}

K e y words: plasma surface alloying, chromizing, oil casing tube, P110 steel, corrosion, wear

\section{Introduction}

The sustainable growth in economy and industry around the world has resulted in too great a consumption of fossil fuels over the past decades. As one kind of the most important sources of energy, oil/gas shows a marked increase in recent years. Therefore, far more oil/gas wells are needed to exploit. It has been reported that oil and natural gas together account for about $60 \%$ of all global energy demands [1]. In the field of oil and natural gas exploration, petroleum tube is an important structural unit of oil well. It takes about $30 \%$ of the entire oil well development cost, and the oil casing tube occupies nearly three quarters of the whole petroleum tube consumes $[2,3]$. The oil casing tubes are prone to deterioration and failure that induced by corrosion and/or wear when they are operated in oil/gas wells (see Fig. 1a) $[4,5]$. Using anticorrosion alloy tubes is the most effective way to guarantee high efficient and safe production. However, anticorrosion alloy contains large amounts of noble metals (e. g. Ni, $\mathrm{Cr}, \mathrm{Mo}$ ), which would add the production cost and might result in the increase of structure [6]. Chromium $(\mathrm{Cr})$ can provide a significant enhancement in the corrosion resistance of steel as its excellent passivation ability [7]. Many scientific institutions have done a great deal of research on development and application of low-chromium alloy steel which is used for the oil casing tube. Therefore, low-chromium steel $(3 \mathrm{Cr}, 5 \mathrm{Cr}$, etc.) appeared subsequently [6]. But the content of $\mathrm{Cr}$ in a monolithic oil casing tube remains great, thus even small improvements in the durability of plain carbon oil casing tube would bring a large economic benefit. In addition to suffering serious corrosion, casing tubes also experience severe wear that originate from the friction between the casing tube and the sucker rod in the course of drilling [8]. The wearing of casing tube can lead to the reduction of collapsing strength

*Corresponding author: tel.:+863516010540; e-mail address: $\underline{\text { nmlz33@126.com }}$ 

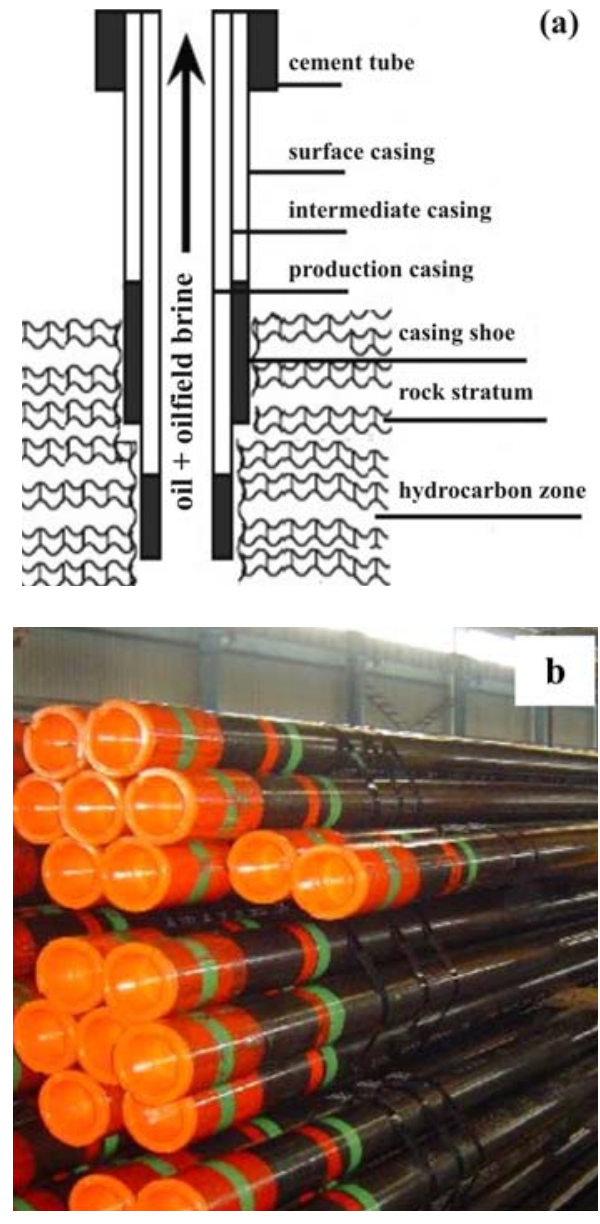

(c)

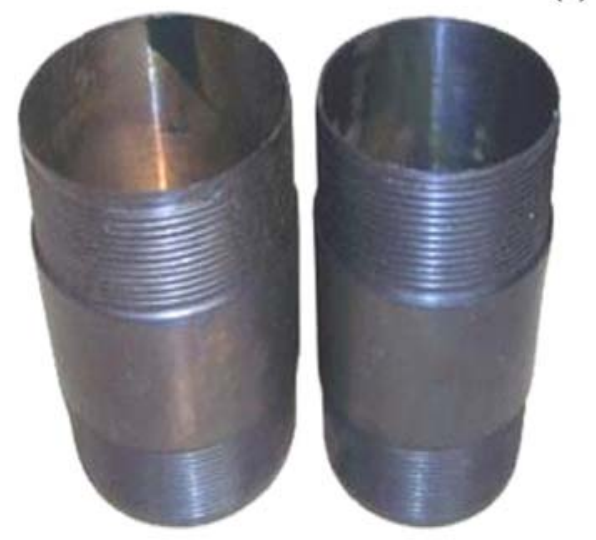

Fig. 1. Open hole completion and well bore structure (a), pictures of oil casing tube (b) and tubing collar (c).

and internal pressure strength, which might result in shortening the service lifetime of oil/gas wells.

It is well accepted that the surface of a component is much more vulnerable to damage than the interior of the component. Most types of material degradation such as wear, corrosion and fracture are usually generated on the surface of a component. Surface engineering is essential to overcome the aforementioned problems [9]. Metallic coatings, such as aluminizing coating (Al-coating), chromizing coating (Cr-coating) and $\mathrm{Al}-\mathrm{Cr}$ simultaneous diffusion coating are normally used to increase the life time of Fe-based materials [9]. Chromizing process has long been found to successfully improve the corrosion and wear resistance of steel components economically since the year of 1919 . Many reports have addressed the studies and applications of chromizing to improve the surface performance of steel components [10-17]. Chromizing is distinguished by providing a compromise between the cost and the performance of materials [9]. According to a short term benefit cost analysis, using oil casing tube made of plain carbon steel has the advantage of lowcost. Therefore, it is feasible to modify the oil casing tube steel by chromizing. Meanwhile, chromizing is a relatively inexpensive technique which can fulfill the requirements of better corrosion and wear resistance.

The present study aims (i) to form chromizing coating on P110 oil casing tube steel (referred to P110 steel in the following) via plasma surface chromizing process; (ii) to analyze the characteristics and exam the corrosion/wear resistance of the chromizing coating.

\section{Experimental procedure}

P110 steel substrate materials were cut from a P110 steel tube by an electric discharge wire-cutting machining in the size of $25 \times 12 \times 5 \mathrm{~mm}^{3}$. Nominal chemical compositions of P110 steel are listed in Table 1. Each specimen was manually ground using $\mathrm{SiC}$ abrasive papers down to $800^{\#}$ and ultrasonically cleaned in acetone bath prior to chromizing treatment. The plasma surface chromizing process was performed on an independent double glow plasma surface alloying equipment (LS-450) developed at Taiyuan University of Technology (Taiyuan, P. R. China). In this work, argon gas (Ar) was selected as the carrier gas. A chromium plate in the size of $150 \times 50 \times 5 \mathrm{~mm}^{3}$, which could provide chromium ions under the plasma sputtering effect, was employed as the target. Figure 2 suggests the schematic diagram of plasma surface chromizing apparatus. In the vacuum chamber, the work piece and the so called source electrode (made up of one or more desired alloying elements) are two negatively charged members and the vacuum bell jar which is earthed is the anode. As shown in Fig. 2, when the two power supplies are put through and reach certain voltage values, both cathode and source electrode are enveloped with a glow discharge under the argon atmosphere. One glow discharge heats the work piece to be surface alloyed, while the second glow discharge bombards the source electrode to sputter- 
Table 1. Chemical compositions (wt.\%) of P110 steel

\begin{tabular}{ccccccccccccc}
\hline $\mathrm{C}$ & $\mathrm{Si}$ & $\mathrm{P}$ & $\mathrm{S}$ & $\mathrm{Mn}$ & $\mathrm{Cr}$ & $\mathrm{Nb}$ & $\mathrm{Ni}$ & $\mathrm{Cu}$ & $\mathrm{Mo}$ & $\mathrm{Ti}$ & $\mathrm{V}$ & $\mathrm{Fe}$ \\
\hline 0.26 & 0.19 & 0.009 & 0.004 & 1.37 & 0.148 & 0.06 & 0.028 & 0.019 & 0.013 & 0.011 & 0.006 & Balance \\
\hline
\end{tabular}

Table 2. Content of electrolyte in simulated oilfield brine

\begin{tabular}{lccccccc}
\hline Electrolyte & $\mathrm{Cl}^{-}$ & $\mathrm{SO}_{4}^{2-}$ & $\mathrm{HCO}_{3}^{-}$ & $\mathrm{CO}_{3}^{2-}$ & $\mathrm{Na}^{+}+\mathrm{K}^{+}$ & $\mathrm{Mg}^{2+}$ & $\mathrm{Ca}^{2+}$ \\
\hline Content $\left(\mathrm{g} \mathrm{L}^{-1}\right)$ & 19 & 1.14 & 0.6 & 0.12 & 12.35 & 1.05 & 0.39 \\
\hline
\end{tabular}

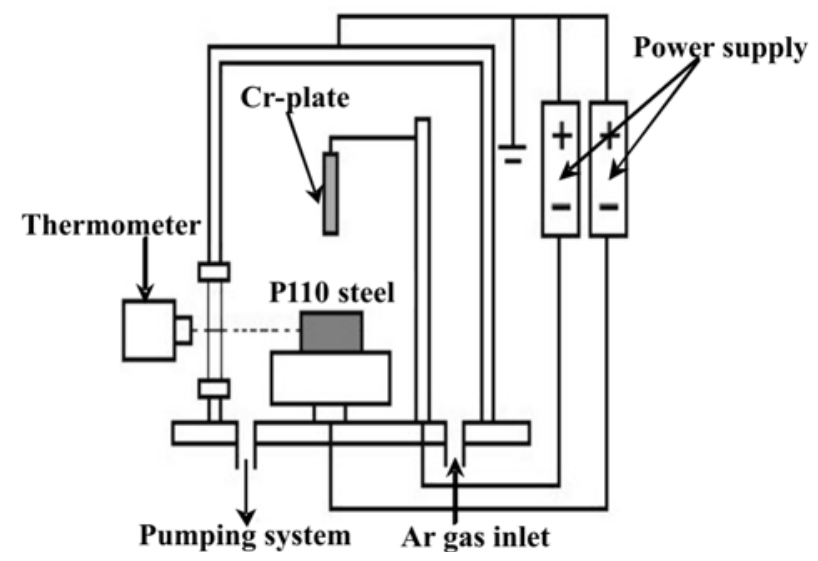

Fig. 2. Schematic diagram of plasma surface chromizing apparatus.

ing the desired alloying elements. The phenomenon is called as the "double glow discharge". The charged ions or particles which are bombarded from the source electrode migrate to and firstly diffuse into the deposit onto the surface of the work piece under the influence of an electric field, and finally, a desirable alloyed surface is obtained [12]. Before chromizing process, the P110 steel samples were subjected to ion bombardment in an Ar glow discharge under negative bias voltages from -900 to $-800 \mathrm{~V}$ for $30 \mathrm{~min}$. The surface alloying process was performed at target voltages from -750 to $-650 \mathrm{~V}$ with a temperature range of $1173-$ $1223 \mathrm{~K}$, P110 steel was performed at voltages from -500 to $-350 \mathrm{~V}$ to maintain a temperature of $1123 \mathrm{~K}$, the distance between the target and the P110 steel sample was $15 \mathrm{~mm}$. The gas pressure in the chamber was maintained ranging in 35-40 $\mathrm{Pa}$ with duration of $3 \mathrm{~h}$. Thereafter, the surface chromium alloyed P110 steel sample was cooled under the argon flow protection in the chamber.

The phase constitution of the chromizing coating was evaluated using X-ray diffraction (XRD) using $\mathrm{Cu} \mathrm{K} \alpha$ radiation. The surface morphology and composition of the obtained coating was investigated using a scanning electron microscope (SEM) equipped with energy dispersive spectrometer (EDS). Microstructural analyses and thickness measurements of the chromizing coating were carried out under the optical microscope (OM). Nital-etched micro-section perpendicular to the surface of the sample was examined. The concentration profile of the elements over the thickness of the chromizing coating was analyzed using glow discharge optical emission spectroscope (GDOES). A micro-hardness tester was used to measure the surface hardness of chromizing coating and P110 steel using a Vickers indenter under a load of $300 \mathrm{~g}$ applied for a dwell time of $15 \mathrm{~s}$.

The corrosion resistance of the chromizing coating was examined by electrochemical tests, including open circuit potential (OCP) and potentiodynamic polarization $[18,19]$. The corrosion medium, $\mathrm{CO}_{2^{-}}$ -saturated simulated oilfield brine, was prepared from reagent grade chemical and distilled water. The chemical composition of simulated oilfield brine is tabulated in Table 2 [18]. The corrosion medium was deaerated by nitrogen gas $\left(\mathrm{N}_{2}\right)$ bubbling for $4 \mathrm{~h}$ and was passed through $\mathrm{CO}_{2}$ for $4 \mathrm{~h}$. The electrochemical experiments were performed with the CS350 electrochemical measurement system, and a traditional three-electrode cell has been applied to perform the mentioned electrochemical tests with a temperature of $303 \mathrm{~K}$ throughout the experiments. The reference electrode was a saturated calomel electrode (SCE) and the counter electrode $(\mathrm{CE})$ was a platinum plate. The specimens of bare P110 steel and chromizing coating were used as the working electrode (WE).

Wear resistance of P110 steel and chromizing coating were evaluated by laboratory tests which were performed on the MFT-R4000 friction-wear testing machine by a reciprocatory type tribometer under sliding in the air. The atmospheric condition in the laboratory involved a temperature of $303 \mathrm{~K}$ and a relative humidity of $40-45 \%$. High carbon chromium bearing steel balls (commonly referred as GCr15 in China) with a diameter of $5 \mathrm{~mm}$ were chosen as the counterparts. For comparative reasons, all the tests were conducted with identical parameters: by wearing against counter balls at $303 \mathrm{~K}$ with a reciprocatory displacement of 


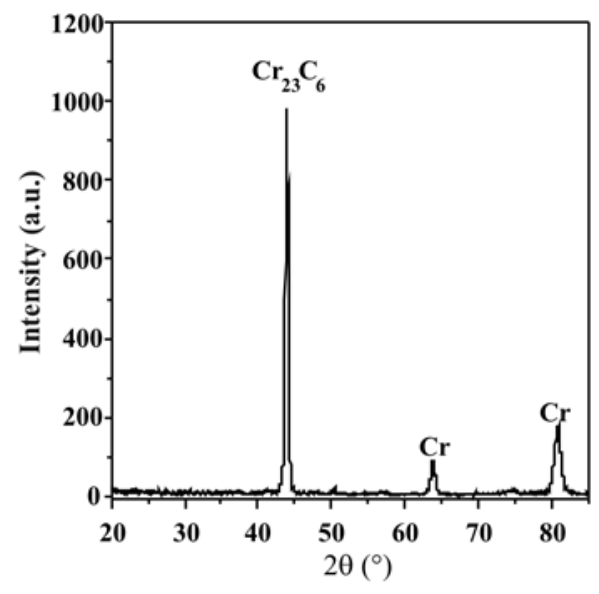

Fig. 3. XRD pattern of chromizing coating.

$5 \mathrm{~mm}$, a normal load of $20 \mathrm{~N}$ with a sliding velocity of $2 \mathrm{~Hz}$ for $30 \mathrm{~min}$. The wear resistance of the samples was defined by comparing the results of mass losses. The specimens were thoroughly cleaned with acetone in an ultrasonic bath before and after every wear test. An analytical balance with an accuracy of $0.01 \mathrm{mg}$ was employed to weigh the original and worn samples. The topographical features of the worn surfaces belonging to the tested samples were also examined using SEM and OM $[20,21]$.

\section{Results and discussion}

\subsection{Microstructural characteristics}

The XRD diffraction pattern of the obtained coating which can help to elucidate the material transformations that take place in the P110 steel surface is shown in Fig. 3. According to the diffraction peak intensity, it can be identified that the obtained coating is mainly composed of $\mathrm{Cr}_{23} \mathrm{C}_{6}$, and this indicates the formation of chromizing coating. It is seen that besides the $\mathrm{Cr}_{23} \mathrm{C}_{6}$ peaks, weak $\mathrm{Cr}$ peaks advent in the XRD pattern, and this may be resulted from the formation of a $\mathrm{Cr}-\mathrm{Fe}$ solid solution in the chromizing coating. Figure 4 shows the surface morphology and composition of the chromizing coating. As shown in Fig. 4, the chromizing coating is uniform and continuous without any micro-cracks. It is noticeable that some protuberances are distributed on the surface of chromizing coating, indicating that the coating developed in an island shape mode. The protuberances may be attributed to the local fusion of $\mathrm{Cr}$ target which are caused by point discharge [12]. The surface composition of the chromizing coating examined by surface EDS scan has further confirmed the formation of chromizing coating. The microstructure of the chromizing coating on P110 steel was analyzed un-

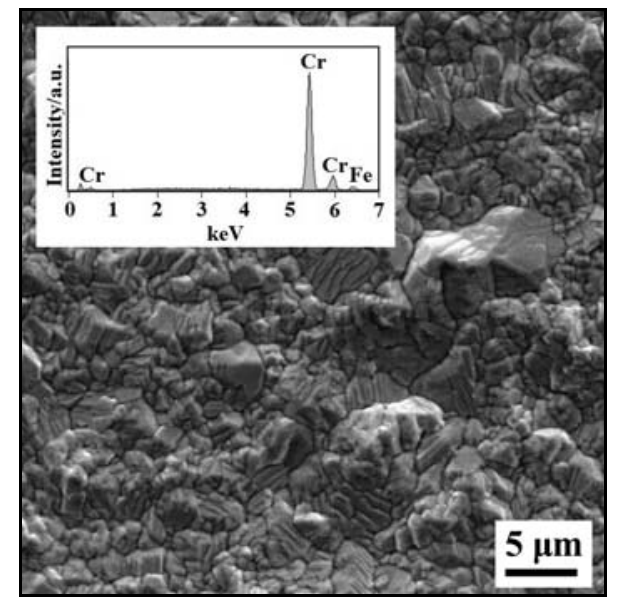

Fig. 4. Surface morphology of chromizing coating.

der an $\mathrm{OM}$ on transverse nital-etched micro-section. A bright, non-etched layer with an estimated thickness of $35 \mu \mathrm{m}$ was observed according to the measuring scale, the obtained coating was dense, uniform and compact, and it was clearly separated from the P110 steel substrate (Fig. 5a). GDOES compositional depth profile is given in Fig. 5b, it is seen that the concentration of $\mathrm{Cr}$ gradually decreases from outside to inside, and the concentration of $\mathrm{Fe}$ tends to increase from the surface to the interior, while the gradient distributing characteristics of $\mathrm{Cr}$ and $\mathrm{Fe}$ in the coating is conducive to improve the bond strength between the coating and the substrate. The thickness of the chromizing coating was approximately $35 \mu \mathrm{m}$, as derived from GDOES analysis, and this is in good agreement with the OM observation.

Generally the wear-resistant chromizing coatings obtained by pack cementation were often produced under higher temperature (above $1273 \mathrm{~K}$ ) and longer holding duration, which are favorable to get a thicker carbide - coating (contains $\mathrm{M}_{23} \mathrm{C}_{6}$ and $\mathrm{M}_{7} \mathrm{C}_{3}$ ) and thinner Cr-deposition layer on the surface of chromizing coating. However, chromizing coating formation conditions with lower temperature of $1123 \mathrm{~K}$ and shorter holding time of $3 \mathrm{~h}$ by plasma surface chromizing process in this work aimed to obtain a promising coating without compromising the mechanical property of P110 steel. Therefore a thicker Cr-deposited layer is indicated in Fig. 5b.

\subsection{Corrosion resistance}

The OCP is a reliable parameter that indicates the tendency of corrosion process, and the measurement of OCP is generally performed to study the chemical stability of the testing sample [22]. The OCP as a function of immersion time for P110 steel and chromizing coating in $\mathrm{CO}_{2}$-saturated simulated oilfield brine is given in Fig. 6. The initial Eocp of P110 steel 

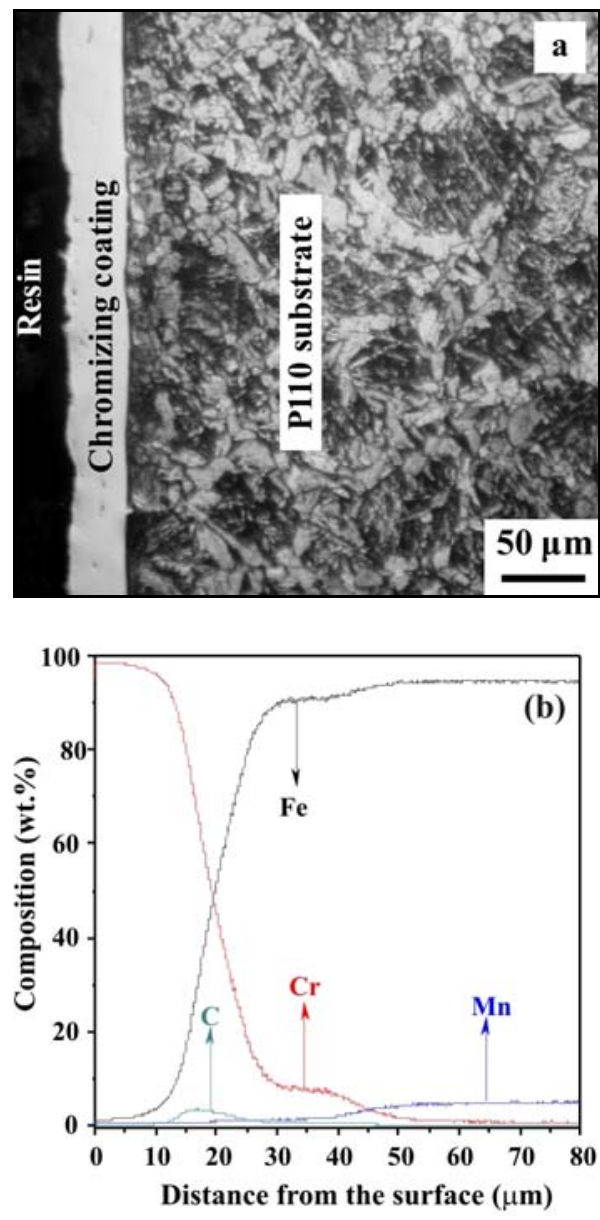

Fig. 5. Cross-sectional microstructure (a) and composition profile of chromizing coating (b).

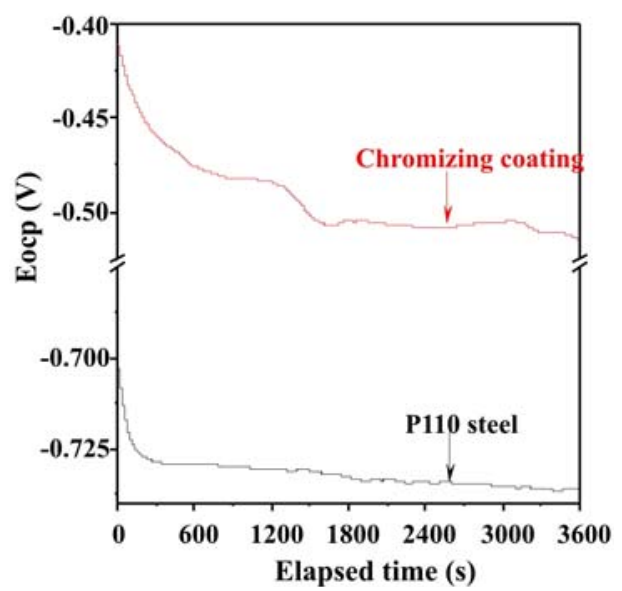

Fig. 6. Eocp vs. time curves of chromizing coating and P110 steel.

and chromizing coating are approximately -0.69 and $-0.41 \mathrm{~V} / \mathrm{SCE}$, respectively. After a certain time, both of the P110 steel and chromizing coating get relat-

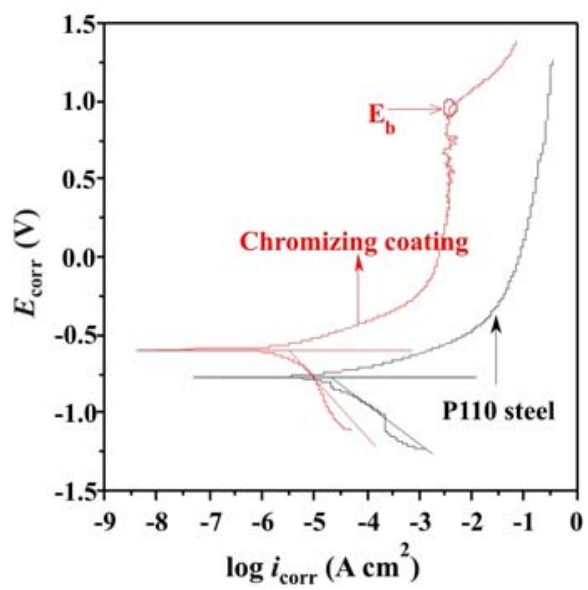

Fig. 7. Polarization curves of chromizing coating and P110 steel.

ively steady Eocp. The potential value for the chromizing coating is about -0.52 and $-0.74 \mathrm{~V} / \mathrm{SCE}$ for P110 steel. This confirms that the chromizing coating has improved the chemical stability of P110 steel against corrosion in $\mathrm{CO}_{2}$-saturated simulated oilfield brine. Chromizing coating can also act as a barrier protecting P110 steel from the corrosive environments by its mechanical isolation effect [23-26]. Figure 7 shows the potentiodynamic polarization curves of $\mathrm{P} 110$ steel and chromizing coating in $\mathrm{CO}_{2}$-saturated simulated oilfield brine. It is seen in Fig. 7 that P110 steel shows no passive zone, its anodic current increases with increasing polarization potential. After the polarization test of P110 steel, the corrosion medium became yellowish green, implying that iron cations entered the solution; P110 steel underwent severe corrosion [22]. It can also be seen from Fig. 7 that the anodic branch of the polarization curve of chromizing coating is characterized by a passive region (from 0 to $0.94 \mathrm{~V}$ ) and breakdown potential (small circle marked in Fig. 7). The existence of passive region for the chromizing coating suggests that the passive film has naturally formed on the surface when it was exposed to the corrosive electrolyte [19]. By using the Tafel extrapolation method, the values corrosion current densities for chromizing coating and P110 steel are $3.452 \times 10^{-6}$ and $2.505 \times 10^{-5}$ A $\mathrm{cm}^{-2}$, respectively. Therefore, it can be concluded that the corrosion resistance of P110 steel was significantly enhanced by chromizing coating on its surface from the thermodynamic and dynamic points of view.

\subsection{Wear resistance}

Based on the micro-hardness corresponding to the measuring points on the surfaces of bare P110 steel and chromized P110 steel, a column chart can be created as shown in Fig. 8a. The chromizing coating is more than two times as hard as P110 steel. The 

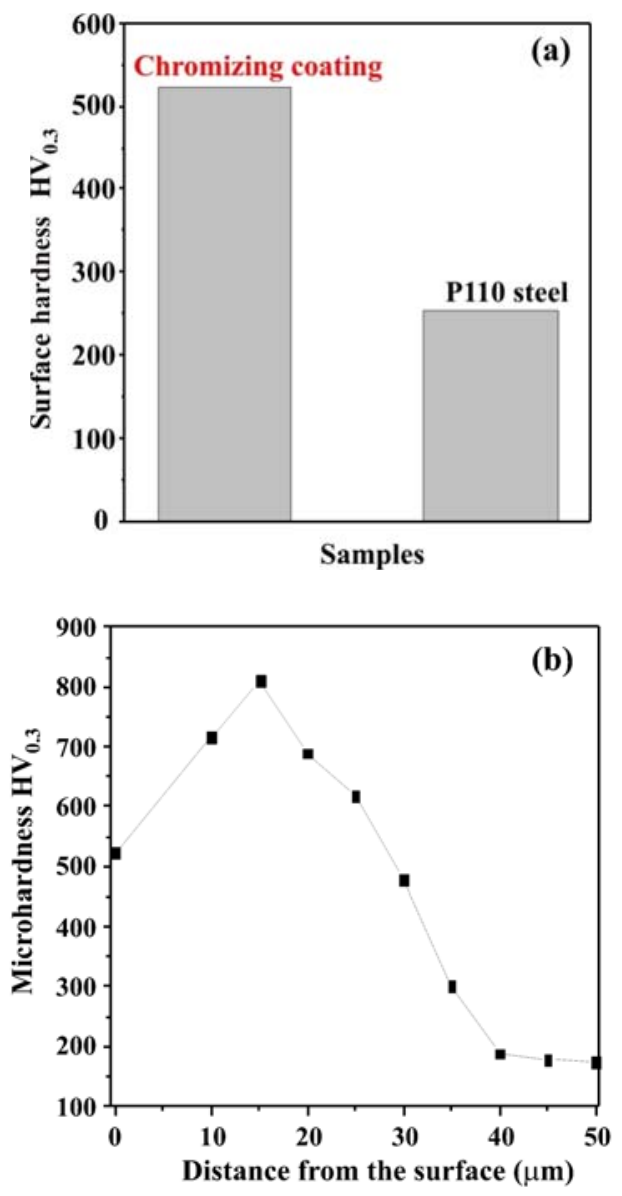

Fig. 8. Surface microhardness values of chromizing coating and P110 steel (a) and microhardness profile (b) of chromizing coating.

higher surface hardness of the chromizing coating is also thought to improve the wear resistance of P110 steel [27]. However, a relatively low surface hardness value in this paper was due to a thick $\mathrm{Cr}$-deposition layer (see Fig. 5b) on the coating surface which resulted from a lower formation temperature of $1123 \mathrm{~K}$ than in other works [11-14]. In accordance with the measuring points along the depth direction of the coating, the microhardness curve of the chromizing coating was plotted, as given in Fig. 8b. It is noted that the hardness distribution of the coating decreases gradually from the near surface to the inside of the coating, and this is mainly attributed to the coating microstructure characteristics. Enhancement of microhardness is connected with structural modification on the near surface of the P110 steel, which is resulted from the formation of chromium carbides in the coating, as shown in Fig. 3.

Figure 9a compares the varying characteristics of the mass losses between the P110 steel and chromizing coating after dry sliding against GCr15, it is notable that the mass loss of the chromizing coating
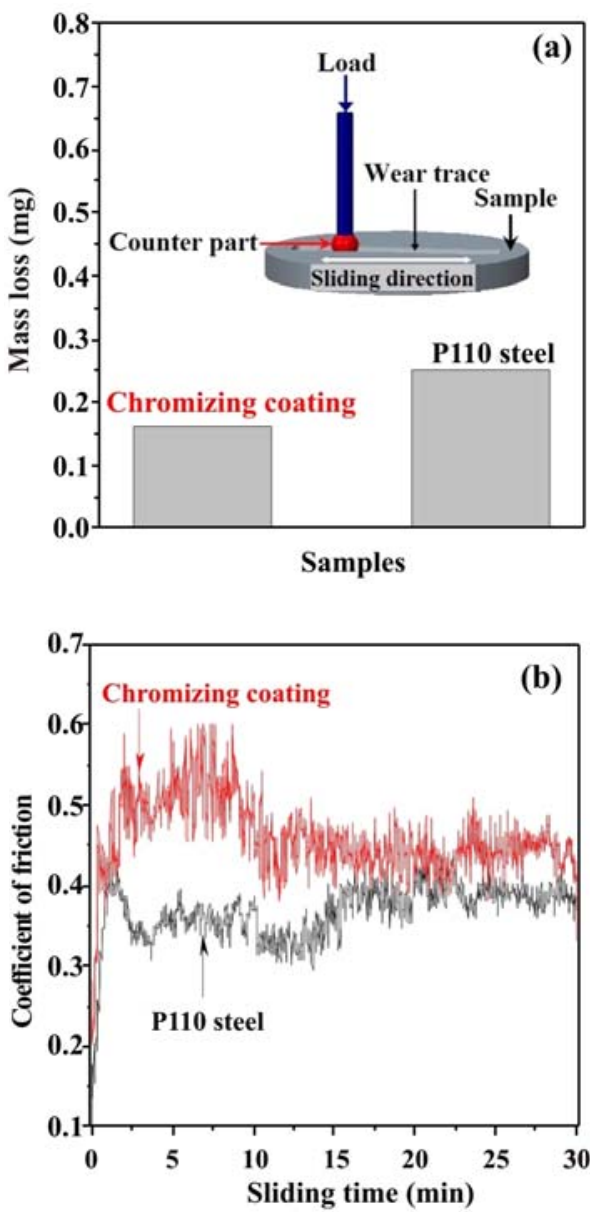

Fig. 9. Mass losses (a) and coefficients of friction (b) of chromizing coating and P110 steel.

$(0.163 \mathrm{mg})$ is lower than that of P110 steel $(0.250 \mathrm{mg})$. The reduction of mass loss of chromizing coating compared with P110 steel can be attributed to the enhancement in surface hardness degree of the coating and high metallurgical bonding strength between the coating and the substrate [28, 29]. Figure 9b indicates the variations of coefficient of friction-time curves for chromizing coating and P110 steel in dry sliding. As shown in Fig. 9b, it is noticeable that chromizing coating exhibited higher coefficient of friction than that of P110 steel. It can be concluded that the coating has no obvious friction-reduction effect when sliding against GCr15. The coefficient of friction belonging to the chromizing coating continually increased for about 7 min up to 0.60 , subsequently reduced and maintained at around 0.45 until the test was completed. It is observed that in the first $10 \mathrm{~min}$, the coefficient of friction P110 steel exhibits a sharp fluctuation characteristic, which indicates the existence of a running-in period in the initial sliding stage $[29,30]$. After then, the coefficient of friction gradually increased and oscillated in the range of $0.35-0.4$. 

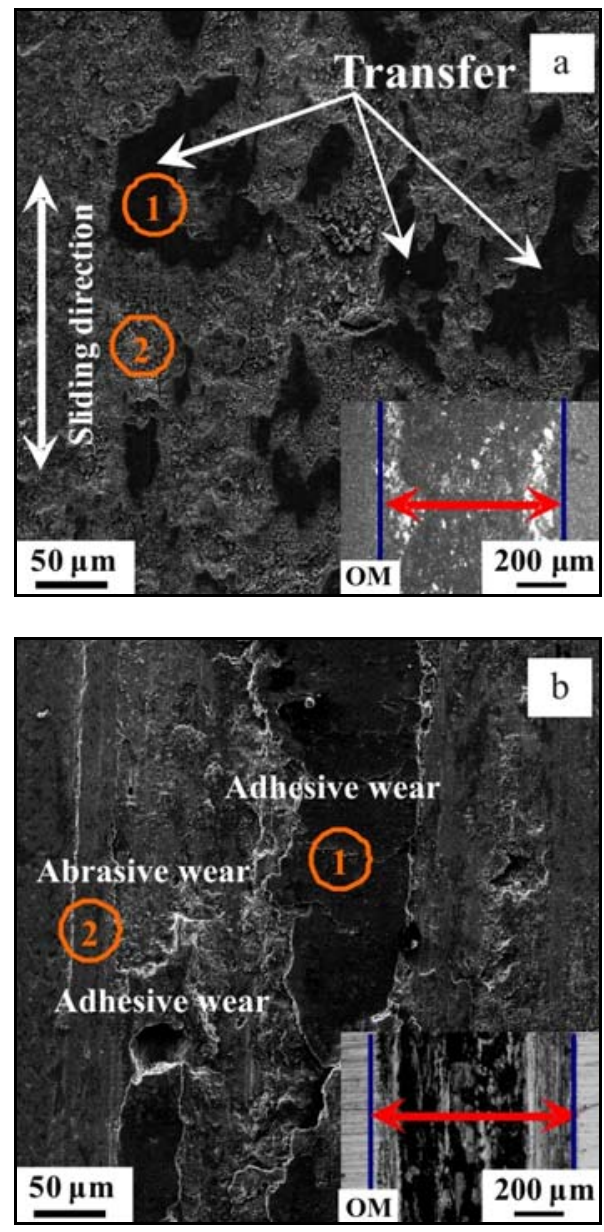

Fig. 10. Wear scars of chromizing coating (a) and P110 steel (b).

Table 3. EDS analysis of worn chromizing coating surface against $\mathrm{GCr} 15$

\begin{tabular}{lccrc}
\hline Element (wt.\%) & $\mathrm{C}$ & $\mathrm{O}$ & $\mathrm{Cr}$ & $\mathrm{Fe}$ \\
\hline Zone-1 & 1.4 & 29.9 & 2.5 & 66.2 \\
Zone-2 & 2.9 & 20.4 & 39.9 & 36.8 \\
\hline
\end{tabular}

Figure 10a displays the whole feature $(\mathrm{OM})$ and enlarged image (SEM) of the wear scar for chromizing coating. On the basis of EDS analyses results in Fig. 10a and in Table 3, zone 1 reveals high Fe content, the Fe presence may be derived in transfer from the GCr15 counter body, whereas the Cr-rich area (zone 2 ) in grey color is the unworn through coating surface. Combining the mass loss results, the predominant wear mechanism of chromizing coating can be deduced as the transfer of counter body material to the coating. The transfer of counterpart might have resulted from the higher hardness of chromizing coating
Ta b le 4. EDS analysis of worn P110 steel surface against GCr15

\begin{tabular}{lcrcc}
\hline Element (wt.\%) & $\mathrm{C}$ & $\mathrm{O}$ & $\mathrm{Mn}$ & $\mathrm{Fe}$ \\
\hline Zone-1 & 0.1 & 10.7 & - & 89.2 \\
Zone-2 & 0.9 & 9.6 & 1.2 & 88.3 \\
\hline
\end{tabular}

than the GCr15 steel [30]. Meanwhile, as presented in Fig. 10, the wear scar width of chromizing coating is not as wide and continuous as that of P110 steel in the OM images (red double-headed arrows marked). There is evidence of plastic deformation on the worn surface of P110 steel in Fig. 10b. However, plastic deformation would increase the adhesive wear [30]. The higher magnified SEM image highlights the severe wear occurred during sliding. Worn surface of P110 steel is very rough, adhesive and abrasive scoring marks are clearly observable. Owing to the high chemical affinity between P110 steel and GCr15 steel counterpart, cold welding or adhesion was prone to occur between the friction pairs. But this kind of linking with a weak bonding strength can be broken by relative motion of the friction pairs, and this resulted in adhesive wear which was indicated by adhesive build-up (zone 1) and further confirmed by EDS in Table 4. Table 4 suggests the presence of $\mathrm{O}$ in zone 1 and zone 2, which revealed the oxidation reaction took place due to the ability of the metal to oxidize under ambient conditions [30]. The main wear mode of P110 steel was adhesive wear associated with oxidation wear and abrasive wear. In accordance with the surface hardness values and mass losses, as well as the surface morphologies of worn chromizing coating and worn P110 steel, chromizing coating provided a promising protection on P110 steel in dry sliding against GCr15 steel counterpart. The wear resistance of P110 steel was significantly improved by chromizing treatment.

\subsection{Limitations and future work}

It is well known that an oil well is usually thousands miles in depth, the casing tubes are connected by collars in the oil well (see Figs. 1b,c) [8, 31, 32]. Of course, the tubing collars play an important role in ensuring the service safety of casing tubes. Due to the adverse factors, such as the length of a casing tube and the capacity of the vacuum chamber, it is difficult to achieve the chromizing treatment of whole casing tubes. However, it is realistic to batch chromizing of tubing collars and realize surface strengthening. The present preliminary results seem promising and it is also needed to carry out further experiments and investigations to obtain an optimal processing parameters for practical application. 


\section{Conclusions}

In this investigation, attempts have been made to fabricate chromizing coating on P110 steel in the employ of plasma surface chromizing to improve the corrosion and wear resistance on its surface. Continuous and compact chromizing coating consisted of $\mathrm{Cr}_{23} \mathrm{C}_{6}$ and $\mathrm{Cr}-\mathrm{Fe}$ solid solution.

Chromizing coating which held higher open circuit potential and lower current density than P110 steel presented excellent corrosion resistance in $\mathrm{CO}_{2}$ -saturated simulated oilfield brine. The protective effect of the chromizing coating was attributed to its desirable chemical stability, passivating ability and mechanical isolation action.

Under the same testing conditions, chromizing coating exhibited higher surface hardness values and lower mass loss than that of P110 steel. Chromizing coating indicated no friction-reduction effect when sliding against GCr15. The wear mode of chromizing coating was mainly the adhesive transfer of GCr15 ball; P110 steel underwent adhesive wear combined with oxidation wear and abrasive wear. P110 steel benefited from high surface hardness after chromizing treatment. It was confirmed that plasma surface chromizing was helpful to obtain excellent corrosion and wear resistance for P110 steel.

\section{Acknowledgements}

This work was supported by the China Postdoctoral Science Foundation No. 2012M520604, the Natural Science Foundation for Young Scientists of Shanxi Province No. 2013021013-2, the Youth Foundation of Taiyuan University of Technology No. 2012L050 \& No. 2013T011, and the Qualified Personnel Foundation of Taiyuan University of Technology No. tyut-rc201157a.

\section{References}

[1] Finšgar, M., Jackson, J.: Corros. Sci., 86, 2014, p. 17. doi:10.1016/i.corsci.2014.04.044

[2] Li, H., Zhang, Y., Han, L.: Steel Pipe, 36, 2007, p. 1.

[3] Li, H., Zhang, Y., Han, L.: Steel Pipe, 37, 2008, p. 1.

[4] Pfennig, A., Bäßler, R.: Corros. Sci., 51, 2009, p. 931. doi:10.1016/j.corsci.2009.01.025

[5] Sun, J., Zhang, G., Liu, W., Lu, M.: Corros. Sci., 57, 2012, p. 131. doi:10.1016/j.corsci.2011.12.025

[6] Ioffe, A., Tetyueva, T., Vyboishchik, M., Knyaźkin, S., Zyryanov, A.: Met. Sci. Heat Treat., 54, 2013, p. 492. doi:10.1007/s11041-013-9537-4

[7] Park, S., Lee, S., Kim, J.: Met. Mater. Int., 18, 2012, p. 975. doi:10.1007/s12540-012-6009-0

[8] Pu, B.: Study on Eccentric Wear and Corruption of Tubing and Wear Proof and Antiseptic Liner Tubing. Master D. Thesis. Beijing, China University of Petroleum Beijing Campus 2007, p. 15.
[9] Hosmani, S.: Metall. Mater. Eng., 19, 2013, p. 65.

[10] Bai, C., Wen, T., Hou, K., Ger, M.: J. Power Sources, 195, 2010, p. 779. doi:10.1016/j.jpowsour.2009.08.036

[11] Wang, Z., Lu, J., Lu, K.: Surf. Coat. Technol., 201, 2006, p. 2796. doi:10.1016/j.surfcoat.2006.05.019

[12] Chi, C., He, Z., Gao, Y., Xu, Z.: J. Univer. Sci. Technol. Beijing, 13, 2006, p. 131.

[13] Zhou, Y., Chen, H., Zhang, H., Wang, Y.: Vacuum, 82, 2008, p. 748 .

[14] Lee, S., Cho, K., Lee, W., Jang, H.: J. Power Sources, 187, 2009, p. 318. doi:10.1016/j.jpowsour.2008.11.064

[15] Yang, L., Yu, H., Jiang, L., Zhu, L., Jian, X., Wang, Z.: J. Power Sources, 195, 2010, p. 2810. doi:10.1016/j.jpowsour.2009.11.018

[16] Peng, X., Yan, J., Dong, Z., Xu, C., Wang, F.: Corros. Sci., 52, 2010, p. 1863. doi:10.1016/j.corsci.2010.02.009

[17] Kasprzycka, E., Senatorski, J., Nakonieczny, A., Babul, T.: J. Mater. Eng. Perform., 12, 2003, p. 693. doi:10.1361/105994903322692493

[18] Lin, N., Li, M., Zou, J., Wang, X., Tang, B.: J. Mater. Eng. Perform., 22, 2013, p. 1365. doi:10.1007/s11665-012-0415-9

[19] Liu, Z., Liu, X., Donatus, U., Thompson, G., Skeldon, P.: Int. J. Electrochem. Sci., 9, 2014, p. 3558.

[20] Wang, X., Zhang, M., Du, B., Li, S.: Surf. Rev. Lett., 19, 2012, p. 1250052-1. doi: $10.1007 / 10.1142 / \mathrm{S} 0218625 \mathrm{X} 12500527$

[21] Kang, Y. H., Yang, J., Ma, J., Fu, L., Bi, Q., Li, F., Liu, W.: Tribol. Inter., 51, 2012, p. 11. doi:10.1016/i.triboint.2012.02.010

[22] Liang, J., Bala, S. P., Blawert, C., Störmer, M., Dietzel, W.: Electrochim. Acta, 54, 2009, p. 3842. doi:10.1016/j.electacta.2009.02.004

[23] Ye, W., Li, Y., Wang, F.: Electrochim. Acta, 54, 2009, p. 1339. doi:10.1016/j.electacta.2008.08.073

[24] Yao, Y., Yao, S., Zhang, L.: Surf. Rev. Lett., 13, 2006, p. 489. doi:10.1142/S0218625X06008724

[25] Ashassi-Sorkhabi, H., Eśhaghi, M.: Corros. Sci., 77, 2013, p. 185. doi:10.1016/i.corsci.2013.07.046

[26] Xu, J., Liu, L., Li, Z., Munroe, P., Xie, Z.: Acta Materialia, 63, 2014, p. 245. doi:10.1016/j.actamat.2013.10.040

[27] Cho, T., Yoon, J., Joo, Y., Zhang, S., Cho, J., Kang, J., Chun, H., Kwon, S., Li, M.: Surf. Rev. Lett., 17, 2010, p. 207. doi:10.1142/S0218625X10013849

[28] Rajinikanth, V., Venkateswarlu, K.: Tribol. Int., 44, 2011, p. 1711. doi:10.1016/j.triboint.2011.06.021

[29] He, L., Tan, Y., Wang, X., Tan, H., Zhou, C.: Surf. Coat. Technol., 244, 2014, p. 123. doi:10.1016/j.surfcoat.2014.01.048

[30] Lin, N., Xie, F., Yang, H., Tian, W., Wang, H., Tang, B.: Appl. Surf. Sci., 258, 2012, p. 4960. doi:10.1016/j.apsusc.2012.01.128

[31] http://www.wsphl.com/tg.asp.

[32] http://free.99114.com/SupplyDetail/297032/986824. shtml. 